\title{
De las leyes estatutarias como vía para una reforma al sistema de seguridad social en pensiones ${ }^{*}$
}

\section{Statutory laws as a way to reform the social security pension system}

\section{$\{\text { Óscar Andrés Blanco Rivera }\}^{* *}$}

Recibido: 15 de diciembre de 20I9. Aprobado: 16 de junio de 2020. Dor: https://doi. org/10.1860I/25390406.n5.01

Abogado Universidad Externado de Colombia. Especialista en Derecho del Trabajo y Seguridad Social. Asesor laboral de empresas. Catedrático posgrado en Universidad Externado de Colombia y Universidad del Rosario. Conjuez de la Sala Laboral de la Corte Suprema de Justicia y del Tribunal Superior de Bogotá. Miembro y exgobernador del Colegio de Abogados del Trabajo. Coautor y autor de varios libros y artículos especializados sobre la materia. 


\section{RESUMEN}

La propuesta de adelantar una futura reforma al sistema de pensiones colombiano a través de una ley estatutaria busca dar una seguridad jurídica al sistema para evitar que, como ha ocurrido con la Ley Ioo de 1993, proliferen sucesivas reformas parciales, bien por el Congreso de la República o por medio de decretos reglamentarios que, aunque no constituyen reformas propiamente dichas, sí introducen modificaciones al sentido original de la ley que han permitido de los jueces numerosas interpretaciones que no se ajustan en un todo al espíritu de la ley original.

\section{Palabras clave}

Reforma, ley estatutaria, control de constitucionalidad, procedimiento de reforma complejo, sistema único general de pensiones.

\section{ABstract}

The proposal to advance a future reform to the Colombian pension system through a statutory law seeks to give legal certainty to the system, to avoid that, as has happened with Law Ioo of I993, successive partial reforms have proliferate, either by the Congress of the Republic, or by means of regulatory decrees that, although they do not constitute actual reforms, they introduce modifications to the original meaning of the law, that have allowed judges numerous interpretations that do not fully conform to the spirit of the original law.

\section{KEYWORDS}

Pension reform, Statutory law, Constitutional review, complex pension reform procedure, Colombian pension system.

\section{RAZÓN de UNA REFORMa PENSIONAL Y DE PROTECCIÓN A LA VEJEZ POR LA VÍA DE UNA LEY ESTATUTARIA}

Si partimos de la consideración de que "La seguridad social es un servicio público de carácter obligatorio que se prestará bajo la dirección, coordinación y control del Estado" ", que debe garantizarse 2 , por constituir uno de los derechos irrenunciables integrados en el capítulo 2 del título II de la Constitución Política de Colombia y formar parte de los derechos fundamentales que se encuentran en conexidad con la vida, la integridad personal, la familia, los

I Constitución Política de Colombia, art. 48 .

2 Const., art. 53. 
derechos del niño, la protección a la vejez, los adultos mayores y los adolescentes, una ley estatutaria como vía legislativa especial resulta expedita para tramitar una reforma pensional con las características de seguridad jurídica que brinda esta clase de leyes especiales.

Sobre el punto anterior, la Corte Constitucional indica que

La Seguridad Social es reconocida en nuestro ordenamiento jurídico como un derecho constitucional fundamental. De esta manera, los artículos 48 y 49 de la Carta Política establecen la seguridad social, por un lado, como un derecho irrenunciable, y por otro lado, como un servicio público, de tal manera que, por la estructura de este derecho, es el Estado el obligado a dirigir, coordinar y controlar su efectiva ejecución. La protección que le otorga el ordenamiento constitucional al derecho a la seguridad social se complementa y fortalece por lo dispuesto en el ámbito internacional pues son varios los instrumentos internacionales que reconocen el derecho de las personas a la seguridad social. Conforme a la jurisprudencia constitucional, el derecho a la seguridad social es un real derecho fundamental cuya efectividad se deriva "de (i) su carácter irrenunciable, (ii) su reconocimiento como tal en los convenios y tratados internacionales ratificados por el Estado colombiano en la materia y (iii) de su prestación como servicio público en concordancia con el principio de universalidad $[\ldots]^{3}$.

Refuerza la calificación de la seguridad social como un derecho fundamental lo consagrado en varios instrumentos internacionales que trae la Corte Constitucional en la Sentencia antes mencionada, algunos de los cuales se nombran a continuación:

Artículo 22 de la Declaración Universal de Derechos Humanos:

Toda persona, como miembro de la sociedad, tiene derecho a la seguridad social, y a obtener, mediante el esfuerzo nacional y la cooperación internacional, habida cuenta de la organización y los recursos de cada Estado, la satisfacción de los derechos económicos, sociales y culturales, indispensables a su dignidad y al libre desarrollo de su personalidad ${ }^{4}$.

Artículo i6 de la Declaración Americana de los Derechos y Deberes del Hombre:

3 Corte Constitucional, Sala Séptima, Sentencia T-ı64 del 22 de marzo de 20I3, M. P.: Jorge Ignacio Pretelt Chaljub.

4 ONU, Asamblea General, resolución 2 I 7 A (III), del io de diciembre de I948, Declaración Universal de los Derechos Humanos, art. 22, https://www.ohchr.org/En/udhr/Documents/Udhr_Translations/spn.pdf 
Toda persona tiene derecho a la seguridad social que le proteja contra las consecuencias de la desocupación, de la vejez y de la incapacidad que, proveniente de cualquier otra causa ajena a su voluntad, la imposibilite física o mentalmente para obtener los medios de subsistencia ${ }^{5}$.

Artículo 9. ${ }^{\circ}$ del Pacto Internacional de Derechos Sociales y Culturales: "Los Estados Partes en el presente Pacto reconocen el derecho de toda persona a la seguridad social, incluso al seguro social"'.

Artículo 9. ${ }^{\circ}$ del Protocolo Adicional a la Convención Americana sobre Derechos Humanos en Materia de Derechos Económicos, Sociales y Culturales:

Toda persona tiene derecho a la seguridad social que la proteja contra las consecuencias de la vejez y de la incapacidad que la imposibilite física o mentalmente para obtener los medios para llevar una vida digna y decorosa. En caso de muerte del beneficiario, las prestaciones de seguridad social serán aplicadas a sus dependientes?

Finalmente, el Código Iberoamericano de la Seguridad Social, aprobado por la Ley 5 I6 de 1999, establece en su artículo I. ${ }^{\circ}$ que la seguridad social es un derecho inalienable del ser humano ${ }^{8}$.

De la lectura de las normas constitucionales e instrumentos internacionales citados, se deduce con toda claridad que el derecho a la seguridad social constituye un conjunto de derechos fundamentales que protegen a las personas en su salud, integridad personal y a quienes están en imposibilidad física o mental para obtener los medios de subsistencia que le permitan llevar una vida digna a causa de la vejez, del desempleo o de una enfermedad o incapacidad común o laboral.

El derecho a la pensión de vejez, invalidez o sobrevivencia constituyen prestaciones que - al tenor de lo expuesto por la Corte Constitucional en reiterada jurisprudencia- protegen a las personas cuando su vejez produce una esperable disminución de la producción laboral, que les dificulta o impide

5 OEA, Ix Conferencia Internacional Americana, Declaración Americana de los Derechos y Deberes del Hombre, http://www.oas.org/es/cidh/mandato/Basicos/declaracion.asp

6 onU, Asamblea General, resolución 2200 A (xxI), del I6 de diciembre de i966, Pacto Internacional de Derechos Sociales y Culturales, art. 9 .

7 oEA, Protocolo Adicional a la Convención Americana sobre Derechos Humanos en Materia de Derechos Económicos, Sociales y Culturales, http://www.oas.org/juridico/spanish/tratados/a-52. html

8 orss, Código Iberoamericano de la Seguridad Social, http://www.oiss.org/wp-content/ uploads/2000/OI/CODIGO_IBEROAMERICANO2.pdf 
obtener los recursos para disfrutar de una vida digna, siendo por demás un derecho irrenunciable que se erige en un derecho fundamental, declarado así por la Corte Constitucional, el cual debe estar revestido de una protección legal que no permita su modificación en cualquier momento para evitar, como ocurre en el presente, un sistema disperso de disposiciones y regulaciones reglamentarias que se prestan para toda clase de interpretaciones.

\section{De las diversas leyes consagradas en la Constitución Política}

La Constitución Política de i99i establece en el capítulo 3, artículos I50 y siguientes, las diferentes clases de leyes que le corresponde hacer al Congreso de la República.

El primer grupo está conformado por las llamadas leyes ordinarias que se refieren, por lo general, a las que versan sobre distintas materias, como las de interpretar, reformar y derogar leyes; expedir códigos en todos los ramos de la legislación; definir la división general del territorio, su creación, eliminación, modificación o fusión de entidades territoriales; variar la residencia de los altos poderes del Estado; determinar la estructura de la administración nacional; crear, suprimir o fusionar ministerios, departamentos administrativos, superintendencias; expedir normas para el cumplido ejercicio de inspección y vigilancia del Gobierno nacional; conceder autorizaciones al Gobierno para celebrar contratos, negociar empréstitos y enajenar bienes nacionales, etc. La Ley Ioo de 1993 forma parte de este grupo de llamadas leyes ordinarias.

La ley del plan persigue aprobar los planes nacionales de desarrollo y de inversiones públicas que hayan de emprenderse o continuarse con la determinación de los recursos y apropiaciones que se autoricen para su ejecución y las medidas necesarias para impulsar el cumplimiento de estos ${ }^{9}$; es decir, tienen una finalidad concreta.

Mediante las llamadas leyes de facultades el Congreso puede revestir, hasta por seis meses, al presidente de la República de precisas facultades extraordinarias para expedir normas con fuerza de ley llamados comúnmente decretos leyes ${ }^{\mathrm{IO}}$ cuando la necesidad lo exija o la conveniencia pública lo aconseje. Son de iniciativa gubernamental y su aprobación requiere la mayoría absoluta de los miembros de una u otra cámara.

Las leyes marco tienen por objeto dictar normas generales y señalar en ellas los objetivos y criterios a los cuales debe sujetarse el Gobierno para

$9 \quad$ Const., art. I50, num.3.

Io Const., art. I50, num. Io. 
organizar el crédito público, el comercio exterior, el régimen de cambio internacional, la política de aranceles, tarifas y demás disposiciones relacionadas con el régimen de aduanas, las actividades financieras, bursátiles, aseguradoras y demás relacionadas con el manejo, aprovechamiento e inversión de recursos captados del público, el régimen salarial y prestacional de empleados públicos, entre otros ${ }^{\mathrm{II}}$.

Por medio de las leyes orgánicas el Congreso sujeta su actividad legislativa. A través de ellas se establecerán los reglamentos del Congreso y de cada una de las cámaras, las normas sobre preparación, aprobación y ejecución del presupuesto de rentas, la ley de apropiaciones, el plan general de desarrollo y las relativas a la asignación de competencias normativas a las entidades territoriales. Requerirán para su aprobación la mayoría absoluta de los votos de los miembros de una y otra cámara ${ }^{\mathrm{I} 2}$.

\section{De las leyes estatutarias}

A diferencia de las anteriores leyes, las leyes estatutarias —objeto central de este artículo- constituyen un mecanismo especial para regular materias que la Constitución consagra, entre otros, como derechos y deberes fundamentales que buscan asegurar la protección de las personas.

Establece el artículo $5^{2}$ de la Carta Política que las siguientes constituyen materias objeto de estas leyes especiales:

a) Los derechos y deberes fundamentales de las personas, los procedimientos y recursos para su protección.

b) La administración de justicia.

c) La organización y régimen de los partidos y movimientos políticos; estatuto de la oposición y funciones electorales.

d) Las instituciones y los mecanismos de participación ciudadana.

e) Los estados de excepción.

f) La igualdad electoral entre los candidatos a la Presidencia de la República que reúnan los requisitos que determine la ley.

De los derechos y deberes fundamentales y los mecanismos para su protección se ocupa el capítulo I del título ir, aplicable ese concepto por extensión a los derechos sociales, económicos y culturales consagrados en el capítulo 2 del mismo título del estatuto fundamental, entre los cuales se encuentra el

I I Const., art. I50, num.i9.

I 2 Const., art. I5 I. 
derecho a la seguridad social consagrado en el artículo 48 adicionado con el AL or del 2005.

Por estas razones, se estima que el mecanismo ideal para adelantar una futura reforma al sistema de seguridad social en pensiones y de protección a la vejez lo constituye un proyecto de ley estatutaria por las características que a continuación se explican.

Las leyes estatutarias se distinguen de las demás leyes porque i) comprenden la revisión previa de exequibilidad del proyecto, fase en la que cualquier ciudadano podrá intervenir para defenderla o impugnarla; ii) pueden tener origen en cualquiera de las cámaras, de las entidades señaladas en el artículo I56 o por iniciativa popular en los casos previstos en la Constitución, excepto los proyectos de leyes a que se refieren los numerales 3, 7, 9, i у y 22 y los literales a, b y e, del numeral is del artículo i50 y otros allí citados, que no incluyen en concreto el sistema de seguridad social y protección a la vejez, significando que en esta materia pueden tener iniciativa por cualquiera de las cámaras; iii) el control previo de la Corte Constitucional se realiza tanto por vicios de procedimiento en su formación como por su contenido material que garantiza una salvaguarda de las materias del proyecto aprobado, las cuales solo podrán ser objetadas por el gobierno por inconveniencia bajo ciertos límites y alcances. Esta especie de protección prevista por la Constitución se convierte en una salvaguarda frente a futuros intentos para reformarla, no un impedimento, pero si una restricción.

Sobre las leyes estatutarias, la Corte Constitucional establece que

Las Leyes Estatutarias constituyen un tipo de leyes de especial jerarquía, que tienen como fin esencial salvaguardar la entidad de las materias que regula, que son: los derechos y deberes fundamentales, así como los procedimientos y recursos para su protección; la administración de justicia; la organización y régimen de los partidos y movimientos políticos, el estatuto de la oposición y las funciones electorales; las instituciones y mecanismos de participación ciudadana; los estados de excepción, y la igualdad electoral entre candidatos a la Presidencia de la República; materias éstas que comportan una importancia cardinal para el desarrollo de los artículos i y 2 de la Carta, pues su regulación especial garantiza la vigencia de principios básicos constitucionales y propende por la consecución de los fines esenciales del Estado. De modo que imprimirle rigurosidad a la aprobación de la regulación de dichas materias y, además, mayor jerarquía a las leyes que las consagren, son medios idóneos para lograr la efectividad de los derechos constitucionales, la salvaguarda de un orden justo, así como la existencia de un sistema democrático y participativo. Si bien cualquier proyecto para convertirse en ley debe cumplir con los siguientes 
requisitos: ser publicado oficialmente por el Congreso antes de darle curso en la comisión respectiva; surtir los correspondientes debates en las comisiones y plenarias de las Cámaras, luego de que se hayan efectuado las ponencias respectivas y respetando los quórum previstos por los artículos I 45 y I 46 de la Constitución; realizar los anuncios del proyecto de ley previo a la discusión y votación en cada una de las comisiones y plenarias, exigencia que también se aplica a los debates sobre los informes de las comisiones de conciliación, los cuales deberán ser publicados por lo menos un día antes de darse su discusión y aprobación; respetar los términos para los debates previstos por el artículo i6o, esto es ocho días entre el primer y segundo debate en cada Cámara, y quince días entre la aprobación del proyecto en una de las Cámaras y la iniciación del debate en la otra; respetar los principios de unidad de materia, de identidad y consecutividad; haber obtenido la sanción gubernamental, que como es obvio, en el caso de las leyes estatutarias, dicha sanción se surte después de que la Corte Constitucional haya efectuado la revisión previa y oficiosa de constitucionalidad y declarado, en consecuencia, que las disposiciones del proyecto se ajustan a la Carta. Además de lo anterior, por tratarse de un proyecto de ley estatutaria, es necesario que el proyecto: (i) haya sido aprobado por mayoría absoluta y (ii) haya sido tramitado en una sola legislatura [... $]^{13}$.

Agrega la sentencia en mención que

Conforme a reiterada jurisprudencia de esta Corte, la Constitución ordena que dentro de la legislatura el proyecto haga tránsito en el Congreso, esto es, que sea modificado y aprobado por las Cámaras en ese lapso, pero la revisión constitucional por la Corte y la sanción presidencial pueden ocurrir por fuera de la legislatura, pues si el trámite que debe ser surtido en una sola legislatura incluyese la revisión por la Corte, o las objeciones y sanción presidenciales, sería prácticamente imposible aprobar, modificar o derogar leyes estatutarias, o éstas tendrían que ser tramitadas en el Congreso con excesiva celeridad, sin una adecuada discusión democrática, e incluso con improvisación ${ }^{\mathrm{I}}{ }^{4}$.

Como se concluye de esta sentencia, el trámite de aprobación de las leyes estatutarias se sujeta al procedimiento dispuesto en el artículo I53 de la Constitución, que establece lo siguiente:

Ibid. 
La aprobación, modificación o derogación de las leyes estatutarias exigirá la mayoría absoluta de los miembros del Congreso y deberá efectuarse dentro de una sola legislatura. Dicho trámite comprenderá la revisión previa, por parte de la Corte Constitucional, de la exequibilidad del proyecto. Cualquier ciudadano podrá intervenir para defenderla o impugnarla ${ }^{15}$.

Como se aprecia en estas normas constitucionales, una de las particularidades que se estipula en el artículo $5^{2}$ es que por medio de ellas pueden aprobarse, modificarse o derogarse "Derechos y deberes fundamentales de las personas y los procedimientos y recursos para su protección”, exigiendo una especial mayoría y debate en una sola legislatura, previa revisión de la Corte Constitucional. Este mecanismo otorga un grado superior de modificación ante cualquier intento de reforma que se persiga por alguno de los intervinientes constitucionales.

\section{Del tRÁmite LegisLativo}

En cuanto al trámite legislativo, la Sentencia C-3I3 del 20 I 4 por medio de la cual la Corte Constitucional declaró exequible en cuanto a su trámite el proyecto de Ley Estatutaria n. 209 del $20{ }_{3}$ Senado y 267 del $20{ }_{3}$ Cámara, se rememoran los presupuestos básicos a tener en cuenta por el Congreso, como los de control constitucional por esa Corte:

La Corte ha establecido y decantado, respecto del anuncio, tanto los presupuestos básicos a tener en cuenta por el Congreso en el procedimiento legislativo, como por esta Sala en el Control constitucional respectivo. Se ha sentado en relación con tales presupuestos: “[...] (i) que se anuncie la votación del proyecto en cada uno de los debates reglamentarios; (ii) que el anuncio lo haga la presidencia de la Cámara o de la respectiva Comisión en una sesión diferente y previa a aquella en la cual debe realizarse la votación del proyecto; (iii) que la fecha de la votación sea cierta, determinada o, en su defecto, determinable; y (iv) que el proyecto no sea votado en sesión distinta a la anunciada previamente [...]" (CI99 de 20 I 2 M.P. Mendoza Martelo). De conformidad con tales supuestos, la Corporación también ha trazado unas reglas de valoración sobre el punto, las cuales son: “- [...] El anuncio no tiene que hacerse a través de una determinada fórmula sacramental o de cierta expresión lingüística, en razón a que la Constitución no prevé el uso de una locución específica para cumplir el mandato 
constitucional.-Es posible considerar cumplido el requisito de anuncio, cuando del contexto de los debates surgen elementos de juicio que permiten deducir que la intención de las mesas directivas ha sido la de anunciar la votación de ciertos proyectos para una sesión posterior.-El anuncio debe permitir determinar la sesión futura en la cual va a tener lugar la votación del proyecto de ley en trámite, de manera que sólo la imposibilidad para establecer la sesión en que habría de tener ocurrencia dicho procedimiento hace de aquel un anuncio no determinado ni determinable, y, en consecuencia, contrario al requisito previsto en el artículo ı6o de la Carta. Para definir lo que debe entenderse por la expresión "determinable", la Corporación ha señalado que expresiones como: "para la siguiente sesión” o "en la próxima sesión”, permiten entender que sí fue definida la fecha y la sesión en la cual el proyecto de ley debe ser votado, con lo cual se considera cumplido el requisito del aviso.-En los casos en que la votación de un proyecto se aplaza indefinidamente, de forma tal que no tiene lugar en la sesión inicial para la cual fue anunciada, las mesas directivas deben continuar con la cadena de anuncios, es decir, están obligadas a reiterar el anuncio de votación en cada una de las sesiones que antecedan a aquella en que efectivamente se lleve a cabo la votación del proyecto $[\ldots]^{16}$.

Bajo este procedimiento se obtiene la declaratoria previa de exequibilidad del proyecto de ley estatutaria, en la que la Corte define el carácter de derecho fundamental al acceso a una pensión y la definición de los conceptos esenciales del sistema de pensiones que persigue cobertura universal, equidad, continuidad, oportunidad en materia de prestación del servicio, solidaridad, sostenibilidad fiscal y las medidas concretas que garanticen los derechos de los afiliados y sus beneficiarios para obtener una pensión de vejez, invalidez o de sobrevivencia, así como promover el acceso a la pensión básica universal o esencial que asegure la cobertura universal de los habitantes del país, tal como se hizo para el sistema general de salud.

\section{Del CONTROL De CONSTItucionalidad}

En la Sentencia C-523 del 2005 la Corte Constitucional afirmó que

El control de constitucionalidad de las leyes estatutarias presenta las siguientes características: Se trata de un control jurisdiccional, por cuanto a la Corte le está vedado estudiar la conveniencia u oportunidad de una norma jurídica. Sus 
fallos son en derecho a partir de la confrontación de un proyecto de ley con la totalidad de la Carta Política; es un control automático, por cuanto no requiere para su inicio de la presentación de una demanda de inconstitucionalidad, según así expresamente lo establece la Constitución en los artículos I53 y 24 I8; es integral, por cuanto de conformidad con el numeral $8^{\circ}$ del artículo $24 \mathrm{I}$ Superior la Corte debe examinar los proyectos de ley estatutaria "tanto por su contenido material como por vicios de procedimiento en su formación”. De tal suerte que el juez constitucional debe confrontar la materialidad del proyecto de ley con la totalidad de la Carta Política; e igualmente, analizar si se presentó o no un vicio de carácter procedimental en su formación; es definitivo, pues de acuerdo con lo dispuesto por el artículo 24 I-8 Superior, le corresponde a la Corte decidir definitivamente sobre la constitucionalidad de los proyectos de leyes estatutarias; es asimismo participativo, por cuanto según los artículos 153 inciso $2^{\circ}$ y $24^{2}$ numeral $\mathrm{I}^{\circ}$, cualquier ciudadano podrá intervenir en el proceso de constitucionalidad con el propósito de defender o impugnar la exequibilidad del proyecto de ley; es un control de constitucionalidad previo, por disposición del artículo i53 de la Constitución, que establece que dicho trámite comprenderá la revisión previa por parte de la Corte Constitucional, de la exequibilidad del proyecto ${ }^{17}$.

Ese carácter de definir la exequibilidad previa del proyecto confrontado con la totalidad de la Carta Política es definitivo, lo que limita el accionar de demandas de inconstitucionalidad y, sobre todo, el ejercicio, en nuestro criterio, del denominado activismo judicial en materia de interpretación y aplicación de las normas de derecho que deben estar sometidas al imperio de la ley ${ }^{18}$, como hoy lo registramos en las tendencias jurisprudenciales en el país.

La Sentencia C-439 del 2016 es ilustrativa con las siguientes distinciones, que permiten abundar en el carácter de las leyes estatutarias:

[...] la Constitución Política, al tiempo que define los diferentes tipos de leyes, también consagra una jerarquía entre las dos grandes categorías normativas, la cual se revela en favor de las leyes especiales (estatutarias y orgánicas) sobre las demás leyes sometidas al trámite ordinario de aprobación (códigos o conjuntos sistemáticos de normas, leyes marco, leyes de facultades extraordinarias, leyes de honores y leyes ordinarias o comunes propiamente dichas, entre otras). Al respecto, es importante destacar que la relación existente entre las

Corte Constitucional, Sentencia C-523 del I9 de mayo del 2005, M. P.: Clara Inés Vargas. Hernández. 
leyes especiales y las leyes ordinarias permite inferir que las primeras, dada su particular caracterización constitucional, actúan en realidad como parámetro general de las segundas, lo que a su vez justifica la supremacía de las leyes especiales frente a las leyes ordinarias. Tal supremacía se ve materializada en la imposibilidad de que estas últimas puedan modificar o derogar materias de ley orgánica o estatutaria, o invadir su órbita de competencia, pues estarían contrariando los dictados de una norma que se ha expedido mediante el trámite especial que la propia Constitución ha previsto para ello. Esto quiere decir, además, que las leyes especiales, orgánicas y estatutarias, "pueden ser utilizadas como parámetro de control de constitucionalidad, en tanto (i) determinan en algunos casos el alcance real de las normas constitucionales y (ii) su contenido, según la Constitución, enmarca los límites a los que deben ceñirse otras leyes, lo cual configura la exigencia de un trámite especial en ciertos temas (trámite de ley orgánica o estatutaria), que debe ser respetado so pena de vulnerar los principios constitucionales que la contienen ${ }^{\mathrm{1}}$.

\section{NOtAS Finales}

A manera de conclusión, podemos afirmar que cuando proponemos que el proyecto de ley de reforma o modificación al sistema general de pensiones y de protección a la vejez sea tramitado mediante un proyecto de ley estatutaria, se persigue que i) la aprobación del proyecto sea por mayoría absoluta de los miembros del Congreso que supone un intenso debate legislativo con características de integralidad y universalidad; ii) la discusión debe adelantarse dentro de una sola legislatura que asegura su rapidez; iii) su trámite comprenderá la revisión anterior por parte de la Corte Constitucional de la exequibilidad del proyecto que asegura su apego a la Constitución, y iv) cualquier ciudadano podrá intervenir para defenderla o impugnarla, lo que asegura la participación de la sociedad.

El artículo I53 exige la aprobación por mayoría absoluta de los miembros del Congreso y hace referencia a que es necesaria la votación, en el caso del Senado, que en la actual legislatura es de ro8 miembros, la mayoría absoluta de al menos 55 senadores. Y en cuanto a la Cámara de Representantes, siendo su número actual de 172 miembros, se exigen 87 votos favorables, lo cual refleja el concepto de que para obtener la mayoría absoluta del Congreso se hace necesario que el asunto sometido a su consideración obtenga para su aprobación una mayoría igual o superior a la mitad más uno del número total 
de miembros de Senado o Cámara, que es bien distinta a la mayoría de los miembros presentes en una sesión de aprobación (mayoría simple) como sucede con los proyectos de leyes ordinarias.

Por lo anterior, reiteramos nuestra propuesta de adelantar la futura reforma pensional y de protección a la vejez como proyecto de ley estatutaria con la finalidad de obtener los beneficios que nos demandan esta clase de leyes especiales en pro de la protección de los derechos y deberes de las personas en materia pensional.

\section{Bibliografía}

oEA, Ix Conferencia Internacional Americana, Declaración Americana de los Derechos y Deberes del Hombre, http://www.oas.org/es/cidh/mandato/Basicos/declaracion.asp

oEA, Protocolo Adicional a la Convención Americana sobre Derechos Humanos en Materia de Derechos Económicos, Sociales y Culturales, http://www.oas.org/juridico/spanish/ tratados/a-52.html

oiss, Código Iberoamericano de la Seguridad Social, http://www.oiss.org/wp-content/ uploads/200O/OI/CODIGO_IBEROAMERICANO2.pdf

onv, Asamblea General, resolución 2 I 7 A (III), del ro de diciembre de I948, Declaración Universal de los Derechos Humanos, https://www.ohchr.org/EN/UdHr/Documents/ UDHR_Translations/spn.pdf

oNu, Asamblea General, resolución 2200 A (xxi), del I6 de diciembre de I966, Pacto Internacional de Derechos Sociales y Culturales.

\section{JURISPRUDENCIA}

Colombia, Corte Constitucional, Sala Plena, Sentencia C-748 del 6 de octubre de 20 I I, M. P.: Jorge Ignacio Pretelt Chaljub.

Colombia, Corte Constitucional, Sala Plena, Sentencia C-439 del I7 de agosto del 20r 2, M. P.: Luis Guillermo Guerrero Pérez.

Colombia, Corte Constitucional, Sala Séptima, Sentencia T-ı64 del 22 de marzo de 2013, M. P.: Jorge Ignacio Pretelt Chaljub.

Colombia, Corte Constitucional, Sala Plena, Sentencia C-313 del 29 de mayo de 2014, M. P.: Gabriel Eduardo Mendoza Martelo. 